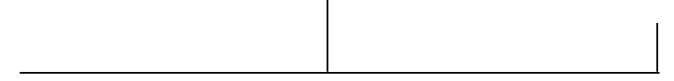

Rev. Latinoam. Psicopat. Fund., São Paulo, v. 12, n. 1, p. 59-70, março 2009

\title{
Da empatia à compreensão do lebenswelt (mundo vivido) na psicoterapia humanista-fenomenológica*
}

Virginia Moreira

\begin{abstract}
A partir da experiencia clínica e tendo como fundamento epistemológico a crítica ao humanismo antropocêntrico com base na fenomenologia antropológica de Maurice Merleau-Ponty, neste artigo descrevo possíveis contribuições da fenomenologia merleau-pontyana para a intervenção em psicoterapia e compreensão da experiência de lebenswelt (mundo vivido) no processo psicoterapêutico.
\end{abstract}

Palavras-chave: Psicoterapia humanista-fenomenológica, empatia, lebenswelt (mundo vivido)

* Este artigo resume parte do trabalho apresentado no X Forum Internacional del Enfoque Centrado en la Persona. Mallorca, Espanha, 7-12 de 2007, sob o título Psicoterapia Humanista Fenomenológica: un desarrollo contemporáneo desde Carl Rogers. 


\section{Introdução}

O que chamamos atualmente de psicoterapia humanista-fenomenológica é um desenvolvimento atual originado na interseção de duas principais vertentes: 1) O pensamento humanista em psicologia de Carl Rogers e 2) O pensamento de autores da psicopatologia fenomenológica, tais como Binswanger, Strauss, Kimura, Minkowski, Tellenbach e Tatossian, entre outros. Do ponto de vista filosófico, a psicoterapia humanista-fenomenológica encontra seu fundamento no âmbito da fenomenologia de Maurice Merleau-Ponty.

A partir da experiência clínica como psicoterapeuta humanista-fenomenológica, neste artigo descrevo possíveis contribuições da fenomenologia merleau-pontyana para a intervenção em psicoterapia e compreensão da experiência de lebenswelt (mundo vivido) no processo psicoterapêutico.

\section{Fundamento epistemológico}

O fundamento epistemológico para a psicoterapia humanista-fenomenológica é a crítica ao humanismo antropocêntrico na psicoterapia de Carl Rogers (Moreira, 2001, 2004, 2005 e 2007). Com base na filosofia de Merleau-Ponty, mais que meramente encontrar uma fundamentação filosófica, venho nos últimos vinte anos repensando, desde Rogers, a teorização de uma psicoterapia humanista-fenomenológica com base em minha prática clínica como psicoterapeuta. Trabalhando como psicoterapeuta, tenho buscado me situar para além das discussões indivíduo-sociedade que perpetuam uma concepção dicotômica do homem, em que a psicologia teria como objeto de estudo o indivíduo. O pensamento merleau-pontyano é ambíguo, superando o pensamento dualista ocidental, sendo sempre movido em uma dialética cíclica, que nunca se fecha. A realidade é opaca, não existem verdades absolutas. O mundo tem contornos múltiplos, assim como a pintura de Cézanne. Influenciado pelo pensamento de Lévi-Strauss, Merleau-Ponty (1960, 1964a, 
1964b e 1970) supera, definitivamente, a dicotomia entre o mundo natural e o mundo cultural através da priorização do significado do lebenswelt (mundo vivido), já que para Merleau-Ponty (1945), assim como a natureza penetra até o centro de nossas vidas pessoais e se entrelaça com ela, igualmente os comportamentos se entrelaçam com a natureza e se depositam na forma de um mundo cultural (Moreira, no prelo).

Não é por acaso que se fala da antropologia fenomenológica de Merleau-Ponty (Muñoz, 1975). O conceito de lebenswelt (mundo vivido), que foi condutor de todo o pensamento ambíguo merleau-pontyano, é, nas palavras de Bidney (1989),

(...) o ponto de conexão entre a antropologia moderna e a fenomenologia. Antropólogos contemporâneos frequentemente descrevem culturas como "os projetos para viver", historicamente construídos pelo homem para a vida em sociedade (...) Cada mundo cultural vivido é um mundo subjetivo; é o mundo histórico criado pelo esforço e o pensamento humano o que tem significado e valor para os membros de uma sociedade em um determinado tempo e lugar. (p. 133)

Quando falamos de mundo, então, estamos falando de um mundo cultural, como enfatiza Merleau-Ponty (1945).

É essa fenomenologia antropológica, que tem como eixo o lebenswelt (mundo vivido), o que faz com que Merleau-Ponty tenha uma definição de humanismo que se diferencia da tradição antropocêntrica. Define o humanismo como "uma filosofia que confronta como problema as relações do homem com o homem e a mútua constituição entre eles de uma situação e de uma história que lhes seja comum" (Merleau-Ponty, 1960, p. 283). A partir dessa perspectiva, em psicoterapia, o cliente, tanto como o psicoterapeuta, são compreendidos como seres intrinsecamente atravessados pelo mundo.

\section{Da empatia à compreensão do lebenswelt}

Ao falarmos de método fenomenológico baseado no pensamento de MerleauPonty e em campos de aplicação na psicoterapia estamos tratando, em primeira instância, de buscar o significado da experiência vivida, ou seja, compreender o lebenswelt, o mundo vivido. Para Merleau-Ponty (1945),

(...) compreender é reapoderar-se da intenção total - não apenas aquilo que são para a representação as "propriedades" da coisa percebida, a poeira dos "fatos históricos", as "ideias" introduzidas pela doutrina -, mas a maneira única de existir que se exprime nas propriedades da pedra, do cristal ou do pedaço de cera, em todos os fatos 
de uma revolução, em todos os pensamentos de um filósofo. (Merleau-Ponty, 1945, p. 17-18)

Trata-se, portanto, de captar os significados da experiência vivida em sua totalidade, que não é puramente objetiva ou subjetiva. O conceito de lebenswelt inclui justamente o entrelaçamento da experiência objetiva com a subjetiva. Ter o lebenswelt como foco em psicoterapia significa focalizar a realidade primária de nossa experiência imediata, o mundo das significações tal como ele se apresenta. O lebenswelt é o segmento da existência mundana vivida pelo indivíduo em sua unicidade. Os conteúdos podem variar de uma sociedade a outra, mas a forma de lebenswelt é única. Sempre há um sentido comum, qualquer que seja seu conteúdo cultural: "É porque meu mundo é sempre, assim, nosso mundo, um mundo intersubjetivo, um mundo comum" (Tatossian, 2006, p. 88). Quando como psicoterapeuta busco compreender o significado do lebenswelt, busco captar esta mistura do vivido, que é, simultaneamente, tanto subjetivo como objetivo, tanto consciente como inconsciente, tanto individual como social e, portanto, ambíguo.

O processo psicoterapêutico se produz na interseção dos lebenswelt do terapeuta e do cliente. O psicoterapeuta passeia de mãos dadas com o cliente em seu lebenswelt (mundo vivido), buscando sempre compreendê-lo, sem nunca separarse de seu próprio lebenswelt. Isto ocorre através da empatia, uma das atitudes básicas postuladas por Carl Rogers. É interessante, inclusive, assinalar que, entre as repetidas definições de seu genial conceito de empatia como atitude básica para o psicoterapeuta facilitador - e é genial em sua simplicidade porque nenhum processo psicoterapêutico que implique em transformações mais profundas pode ser levado adiante com êxito se não ocorre a empatia -, Rogers (1977), em um de seus textos teóricos mais recentes, afirma que o psicoterapeuta ser empático "significa penetrar no mundo perceptual do outro e sentir-se totalmente relaxado dentro deste mundo" (p. 73). O conceito de "mundo perceptual", na realidade, estaria muito próximo de lebenswelt, mundo vivido. Ou seja, a empatia possibilita que o psicoterapeuta não somente "penetre" no mundo do cliente, como se mova na companhia do cliente, buscando a compreensão de sua experiência vivida.

Em minha experiência como psicoterapeuta, observo que com alguns pacientes - ou clientes ${ }^{1}$ - posso mover-me com mais desenvoltura em seu lebenswelt que com outros. Isto ocorre quando vejo esta pessoa mais vezes ou com sessões duas vezes por semana ou por mais tempo, quando o processo já está mais avançado;

1. Utilizo-me das duas denominações sem problemas, dado que entendo criticamente os dois termos: paciente tem o peso da denominação tradicional médica, como passivo; cliente tem o peso comercial do mundo capitalista no qual vivemos (Moreira, 2001, 2007). 
ou seja, quando, de alguma maneira, sinto mais intimidade com o paciente. Seu mundo e, principalmente, sua forma de funcionar neste mundo passam a ser familiares para mim, ainda que, como bem nos recorda Rogers (1977), eu passe a perceber as emoções, medos e desejos do cliente "como se" fosse ele. Não obstante, "se perdemos esta condição de 'como se' teremos um estado de identificação" (p. 72). Neste momento, ser empática flui, o que possibilita que eu me mova também mais livremente no lebenswelt do cliente. Nessas situações psicoterapêuticas me sinto solta, como se seu mundo vivido passasse a ser familiar para mim; posso rir junto com o paciente, ser irônica ou mesmo mais agressiva em minhas intervenções, o que faz o processo também fluar mais rápido e as mudanças pessoais no cliente se intensificarem.

Uma metáfora preciosa para este processo é descrita por Maria Bowen (1987) em seu brilhante texto "Psicoterapia: o processo, o terapeuta, a aprendizagem", em que ela faz uma analogia entre o psicoterapeuta e o Sherpa, um guia membro de uma tribo montanhosa no Nordeste do Nepal. O psicoterapeuta teria, tal como o Sherpa, quatro características importantes que facilitariam a viagem (em meu modo de entender, através do lebenswelt do paciente):

I. O psicoterapeuta não elege o destino ou o caminho a percorrer neste mundo, ainda que ele conheça vários caminhos. Como psicoterapeuta, me utilizo de lentes que muitas vezes (mas não sempre: por mais empática que eu possa ser como terapeuta, como ser humano mundano às vezes me equivoco) me possibilitam ver nos caminhos do lebenswelt do cliente aspectos que ele mesmo por si só não havia sido capaz de ver. Quando faço uma intervenção desse tipo, sempre tenho o cuidado de fazê-la hipoteticamente, quer dizer, a proponho como algo a ser pensado e avaliado pelo cliente. O tom da colocação é, então, importante, como parte da expressão contida na intervenção hipotética. Como o Sherpa, sei que a viagem que fazemos juntos se dá no mundo do cliente, ainda que o meu esteja presente - com minhas experiências pessoais e conhecimentos teóricos, por mais que eu os ponha em suspenso. Como nos lembra Merleau-Ponty (1945), o maior ensinamento da redução fenomenológica é que ela nunca se completa, ou seja, por mais que eu ponha os conteúdos de meu mundo vivido entre parênteses, no sentido de, sendo empática, perceber o mundo vivido do cliente na perspectiva dele, isto nunca se produz completamente, nunca vou livrar-me totalmente de meu próprio lebenswelt, que me constitui. É assim que o processo terapêutico se desenvolve na interseção dos lebenswelten do cliente com o meu, a psicoterapeuta.

II. O psicoterapeuta conhece bem a região. Isto significa que como psicoterapeuta me utilizo de meus conhecimentos teóricos e de vida, de minha experiência como um todo - objetiva e subjetiva - para compreender, com o cliente, os significados de sua experiência vivida. Assim é que, em minha experiência clínica, os estudos eminentemente descritivos em psicopatologia fenomenológica frequente- 
mente me são muito úteis para a compreensão do sofrimento do cliente. Compreender os significados deste sofrimento em seu lebenswelt possibilita, por sua vez, a mudança pessoal almejada na psicoterapia. Contudo, é importante sempre ter em conta que o que vejo o vejo com minhas lentes (teóricas e experienciais). O que vê meu cliente com suas lentes em sua própria construção de seu conhecimento a respeito desta região - seu lebenswelt - é único em sua singularidade e é sempre primeiro, por mais que eu conheça bem esta região (e lhe possa até emprestar minhas lentes em alguns momentos).

III. O psicoterapeuta, como o Sherpa, divide a carga com o cliente. Na experiência clínica o que vejo é que, frequentemente, isto por si só já representa muito para o paciente, que sofre sempre de uma extrema solidão, por mais que esteja cercado de pessoas. Sua solidão é, frequentemente, fruto da sensação de não ser compreendido em sua dor. Dividir a carga desta dor passa a ser, então, um primeiro momento na psicoterapia tendo um grande significado. Em um segundo momento o cliente não somente dividirá a carga, mas também se sentirá compreendido pelo psicoterapeuta - ele deixa de estar só em seu lebenswelt. Quando se permite receber a visita do psicoterapeuta em seu lebenswelt, o que o paciente vivencia objetivamente e subjetivamente, este pode não somente ser compartilhado, mas também compreendido! A genialidade de Rogers em seu momento histórico (Moreira, 2001) o levou a identificar este momento do processo psicoterapêutico, postulando, portanto, que as três condições facilitadoras - a empatia, a congruência e a aceitação - seriam suficientes para o processo de mudança. Em minha experiência estas condições são sempre necessárias. Contudo, nem sempre são suficientes. Às vezes a mudança ocorre neste segundo momento, mas em alguns casos, um trabalho de aprofundamento dos conteúdos que estruturam o lebenswelt do paciente são também necessários. Portanto, sentir--se compreendido e aceito será sempre necessário, mas nem sempre suficiente. Quando é necessário o terceiro momento para que ocorra a mudança, em minha experiência como psicoterapeuta as técnicas de intervenção fenomenológicas (Moreira, 2001) são fundamentais. Entre elas a descrição repetida dos conteúdos (ou, como chamava Fritz Perls, descascar a cebola) funcionará como motor do processo psicoterapêutico, em conjunto com outras técnicas de intervenção clínica tais como a fala autêntica, em que o psicoterapeuta busca que se formule na psicoterapia uma fala sua e do paciente - pela primeira vez, portanto inovadora (Amatuzzi, 1989); ver e ouvir fenomenologicamente, que significa ver o invisível e ouvir realmente o outro - "ouvimos para além das palavras, mesmo quando é através delas" (Amatuzzi, 1990, p. 90); a redução fenomenológica (Merleau-Ponty, 1945), em que duvido de minha própria experiência pondo entre parênteses os conteúdos desta; ou a intuição eidética, que tem como objetivo apreender o significado da experiência (Merleau-Ponty, 1964a e 1964b). 
IV. Finalmente, o psicoterapeuta crê que a psicoterapia é um instrumento de crescimento pessoal e de tratamento eficaz, assim como o Sherpa crê que Shambala está lá e que cada um somente chegará lá através de seu próprio caminho. Como psicoterapeuta tenho escutado com alguma frequência o desejo dos pacientes de ter uma garantia de que a psicoterapia lhes vai ajudar. Obviamente a psicoterapia é um processo extremamente subjetivo e singular, cada caso é um caso, portanto não tenho as receitas rápidas, tão desejadas e vendidas em nossa contemporaneidade fast-tudo (Moreira, 2002). Tampouco posso garantir o êxito de um processo terapêutico, dado que isto depende de muitas variáveis, mas, principalmente, da entrega do paciente à psicoterapia, não como paciente passivo, mas como paciente ativo, dono de sua própria existência contingente, portanto, mundana. Algumas vezes me escutei dizendo algo no sentido de eu "não poder vender um selo de garantia" da psicoterapia ao cliente (o que seria uma atitude pouco séria e irresponsável), mas que se eu não acreditasse profundamente no trabalho que realizo há tantos anos, não mais trabalharia como psicoterapeuta. Quando tenho uma fala deste tipo estou sendo autêntica e congruente (atitudes terapêuticas postuladas por Rogers), por um lado, mas estou também assumindo uma posição como o Sherpa, quando crê que Shambala está lá. Da mesma forma, quando não passo a desejada receita a meu cliente, é por ter toda a convicção de que não existe a receita (assim como não existe o mapa do caminho na região a ser percorrida pelo Sherpa). O caminho terá que ser construído pelo cliente, quiçá com minha ajuda profissional.

Acreditar no poder de mudança do processo terapêutico de base humanistafenomenológica significa crer na tendência atualizante do cliente. Este conceito pilar do Enfoque Centrado na Pessoa postula que a natureza humana é fundamentalmente construtiva e autorregulada (Rogers, 1957 e 1961). No contexto mesmo das psicoterapias humanistas, autores como Perls (1981) e May (1987) discordam de Rogers, destacando a agressividade e a destrutividade como parte da natureza humana (Moreira, 2001 e 2007).

Minha experiência clínica se contrapõe à de Rogers com respeito a este tema, encontrando mais afinidade teórica com o enfoque humanista existencial de Rollo May (1980) neste ponto. Meu trabalho como psicoterapeuta tem como base minha crença na capacidade de crescimento de meu paciente ativo. Não obstante, este mesmo paciente que tem sua tendência construtiva tem também sua tendência destrutiva. Em processos mais longos estas duas tendências se mostram mais claramente, como que se alternam, se complementam. O objetivo do processo terapêutico passa a ser, neste sentido, fortalecer cada vez mais (ou deixar aparecer, como diria Rogers) a tendência atualizante, que é positiva e construtiva, e minimizar, ao máximo, a tendência destrutiva do cliente que também se mostra em muitos momentos do processo. Isto pode ser observado nos momentos em que o 
cliente como que desconstrói ganhos alcançados, tem retrocessos em seu processo de crescimento ou recaídas, como chamo simplesmente, reconhecendo o humano, demasiado humano do qual nos falava Nietzsche. Observando e pensando a prática clínica, tanto a minha como psicoterapeuta, como as de meus alunos em supervisão de estágio em clínica, imagino um gráfico para o processo terapêutico exitoso, em que o processo oscila como em ondas do mar, tem altos e baixos sempre; e, ainda que com o desenvolvimento exitoso do processo os baixos sejam cada vez menos baixos, ou seja, menos dolorosos e imobilizadores, os altos e baixos vão estar sempre presentes no processo psicoterapêutico, assim como na vida. Com o tempo, na medida em que o cliente conhece melhor os caminhos de seu lebenswelt, ele passa a identificar, também, quais são os melhores caminhos, as estradas mais seguras, as ruas sem saída de seu mundo vivido; em outras palavras, ele passa a conhecer melhor seu próprio modo de funcionar no mundo, identificando mais claramente seus limites e suas potencialidades. Na medida em que aprende sobre seu lebenswelt, o cliente aprende sobre os significados de sua experiência vivida, tanto os significados negativos como os positivos, tanto sobre seus ganhos como sobre suas perdas. É assim que o processo terapêutico é ambíguo, tanto como é ambíguo o próprio funcionamento humano, fruto tanto da tendência atualizante quanto da tendência destrutiva que se alternam, se entrelaçam, se mesclam, se constituem mutuamente.

\section{Caminhos}

A psicopatologia fenomenológica, representada na atualidade especialmente pelo pensamento de Tatossian (2006), é sem dúvida uma contribuição notável a ser integrada na clínica humanista-fenomenológica que tem como objetivo investigar e compreender os significados do lebenswelt, o que inclui a experiência psicopatológica vivida. Ademais, na medida em que estamos falando de um desenvolvimento teórico metodológico de caráter experiencial, com base em uma fenomenologia mundana, os estudos mais recentes da área da antropologia da experiência, tais como os desenvolvidos por Kleinman (1988 e 1995) e Good (1992) podem ser uma contribuição bastante enriquecedora, na medida em que trabalham baseados na noção de cultura definida como a interseção entre o significado e a experiência (Kleinman \& Good, 1985; Moreira, no prelo).

É importante destacar que a proposta de uma psicoterapia humanista-fenomenológica proposta não se contrapõe à proposta de Carl Rogers. Entendo-a como um desenvolvimento desde a crítica, reconstrução e continuidade de seu pensamento. Muito mais pesquisas precisam ser realizadas para pensar esta abordagem em psi- 
coterapia. Neste sentido, quem sabe, este artigo pode servir como um convite a estudiosos humanistas que perseguem a utopia de que nos falava Paulo Freire em seu humanismo.

Agradecimento: Aos meus alunos do grupo de Formação em Psicoterapia Humanista-Fenomenológica, pela interlocução valiosa para a construção das ideias desenvolvidas neste artigo.

\section{Referências}

Amatuzzi, M. O resgate da fala autêntica. Campinas: Papirus, 1989.

. O que é ouvir. Estudos de Psicologia, Campinas, v. 7, n. 2, p. 86-97, 1990.

BIDNEY, D. Phenomenological method and the anthropological science of the cultural life-world. In: Natanson, M. Phenomenology and the Social Sciences. Evanston: Northwester University Press, 1989.

Bowen, M. Psicoterapia: o processo, o terapeuta, a aprendizagem. In: SAntos, A.; Rogers, C.; Bowen, M. Quando fala o coração. Porto Alegre: Artes Médicas, 1987. p. 55-66.

Good, B. Medicine, Rationality, and Experience: An Anthropological Perspective. Cambridge: Cambridge University Press, 1992.

Kleinman, A. Rethinking Psychiatry: Cultural Category to Personal Experience. New York: Free Press, 1988.

. Writing at the Margin: Discourse Between Anthropology and Medicine.

Berkeley: University of California Press, 1995.

; Good, B. Culture and Depression. Studies in the Anthropology and Cross-

Cultural Psychiatry of the Affect and Disorder. Berkeley: University of California Press, 1985.

May, R. Psicologia existencial. Porto Alegre: Globo, 1980.

. The problem of evil: an open letter to Carl Rogers. Journal of Humanistic

Psychology, Alameda, CA, v. 22, n. 3, p. 10-12, jul.1987.

Merleau-Ponty, M. Phénoménologie de la perception. Paris: Gallimard, 1945. . Signes. Paris: Gallimard, 1960. . Le visible et l'invisible. Paris: Gallimard, 1964a. . L'oeil et l'esprit. Paris: Gallimard, 1964b. 
. La doute de Cézanne. In: Merleau-Ponty, M. Sens et non sens. Paris: Nagel, 1970. p. 15-44.

Moreira, V. Mas allá de la persona: hacia uma psicoterapia fenomenológica mundana. Santiago: Editorial Universidad de Santiago de Chile, 2001.

. Parte II - Psicopatología Crítica. In: Moreira, V.; Sloan, T. Personalidade, ideologia e psicopatologia crítica. São Paulo: Escuta, 2002. p.109-248.

. O método fenomenológico de Merleau-Ponty como ferramenta crítica na pesquisa em psicopatologia. Psicologia: Reflexão e Crítica, Porto Alegre, v. 17, n. 3, p. 447-456, 2004.

. Ecology in the multiple contours of psychopathology. Revista Latinoamericana de Psicopatologia Fundamental, São Paulo, v. 8, n. 1, p. 54-63, mar. 2005. . De Carl Rogers a Merleau-Ponty: a pessoa mundana em psicoterapia. São Paulo: Annablume, 2007.

. Psicología humanista-fenomenológica. In: Stecher, A.; Paulino, A. (Ed.). Materiales para una cartografía de la psicología contemporánea: tradiciones teóricas y campos profesionales - v. I. Santiago: LOM. No prelo.

Muñoz, J. La antropologia fenomenológica de M. Merleau-Ponty. Madrid: Fragua, 1975.

Rogers, C. A note on the "nature of man". Journal of Counseling Psychology, v. 4, n. 3, p. 100-104, 1957.

. Tornar-se pessoa. São Paulo: Martins Fontes, 1961.

. Uma maneira negligenciada de ser: a maneira empática. In: Rogers, C.;

Rosenberg, R. A pessoa como centro. São Paulo: EPU, 1977. p. 69-90.

PERLS, F. A abordagem gestáltica e testemunha ocular da terapia. Rio de Janeiro: Zahar, 1981.

Tatossian, A. Fenomenologia das psicoses. São Paulo: Escuta, 2006.

\section{Resumo}

(De la empatía a la comprensión del Lebenswelt [mundo vivido] en la psicoterapia humanista-fenomenológica)

A partir de la experiencia clínica y teniendo como fundamento epistemológico la crítica al humanismo antropocéntrico basado en la fenomenología antropológica de Maurice Merleau-Ponty, en este artículo describo posibles contribuciones de la 
fenomenología merleau-pontyana para la intervención en psicoterapia y comprensión de la experiencia del lebenswelt (mundo vivido) en el proceso psicoterapéutico.

Palabras claves: Psicoterapia humanista-fenomenológica, empatía, lebenswelt (mundo vivido)

(De l'empathie à la compréhension du Lebenswelt (monde vécu) dans la psychothérapie humaniste-phénoménologique)

Dans cet article, nous décrivons les possibles contributions de la phénoménologie de Merleau-Ponty à l'intervention en psychothérapie et à la compréhension de l'expérience du Lebenswelt (monde vécu) dans le processus psychothérapeutique. Nous prenons comme base l'expérience clinique et comme fondement épistémologique la critique de l'humanisme anthropocentré à partir de la phénoménologie anthropologique de Maurice Merleau-Ponty,

Mots clés: Psychothérapie humaniste-phénoménologique, empathie, lebenswelt (mond vécu)

(From empathy to understanding of lebenswelt (living world) in humanisticphenomenological psychotherapy)

This present article is based on clinical experience and takes Maurice MerleauPonty's criticism of anthropocentric humanism. from anthropological phenomenology, as its epistemological foundation. Possible contributions from Merleau-Ponty's phenomenology to psychotherapeutic intervention are discussed as well as the understanding of lebenswelt (lived world) in the psychotherapeutic process.

Key words: Humanistic-phenomenological psychotherapy, empathy, lebenswelt (lived world)

Citação/Citation: MoreIRA, V. Da empatia à compreensão do lebenswelt (mundo vivo) na psicoterapia humanista-fenomenológica. Revista Latinoamericana de Psicopatologia Fundamental, São Paulo, v. 12, n. 1, p. 59-70, mar. 2009.

Editor do artigo/Editor: Prof. Dr. Manoel Tosta Berlinck.

Recebido/Received: 1.10.2007 / 10.1.2008 Aceito/Accepted: 8.10.2007 / 10.8.2008

Copyright: @ 2009 Associação Universitária de Pesquisa em Psicopatologia Fundamental/ University Association for Research in Fundamental Psychopathology. Este é um artigo de livre acesso, que permite uso irrestrito, distribuição e reprodução em qualquer meio, desde que o autor e a fonte sejam citados/This is an open-access article, which permits unrestricted use, distribution, and reproduction in any medium, provided the original author and source are credited. 
Financiamento/Funding: $\mathrm{O}$ autor declara não ter sido financiado ou apoiado/The author has no support or funding to report.

Conflito de interesses: $\mathrm{O}$ autor declara que não há conflito de interesses/The author declares that has no conflict of interest.

\section{Virginia Moreira}

Psicóloga; Psicoterapeuta humanista-fenomenológica; Doutora em Psicologia Clínica pela Pontifícia Universidade Católica de São Paulo - PUC-SP (São Paulo, SP, Brasil); Pós-doutorada em Antropologia Médica pela Harvard Medical School (CAPES/Fulbright); Docente Titular da Universidade de Fortaleza - Unifor (Fortaleza, CE, Brasil); Visiting Lecturer do Departamento de Medicina Social de Harvard Medical School; Supervisora Clínica Especialista em Psicoterapia credenciada pela Sociedad Chilena de Psicología Clínica (Santiago do Chile, Chile); Membro da Associação Universitária de Pesquisadores em Psicopatologia Fundamental (São Paulo, SP, Brasil).

Universidade de Fortaleza - Unifor

Mestrado em Psicologia

Av. Washington Soares, 1321

60811-341 Fortaleza, CE - Brasil

e-mail: virginiamoreira@unifor.br 